\title{
ANALISIS EFEK SISTEM JAMINAN DAN PENERAPAN KESEHATAN, SERTA KESELAMATAN KERJA TERHADAP KARYAWAN PT. BATAMEC SHIPYARD BATAM
}

\author{
ANALYSIS OF SECURITY SYSTEM AND IMPLEMENTATION OF HEALTH \\ AND SAFETY TOWARDS EMPLOYEES PT. BATAMEC SHIPYARD BATAM
}

\author{
Debby Endayani Safitri \\ Universitas Muhammadiyah Prof Dr. Hamka, Indonesia \\ riby_42na@yahoo.com
}

\begin{abstract}
Abstrak
Masalah keselamatan secara umum pada PT. Batamec Shipyard Batam masih perlu mendapatkan perhatian.Data cedera yang pernah terjadi yang bersifat ringan bahkan menimbulkan kematian menunjukan bahwa kecelakan kerja pernah terjadi pada tahun 2014-2015. Berdasarkan informasi dari pihak manajemen penelitian tentang penegendalian risiko ini jarang dilakukan, sementara di sisi lain fakta menujukan terjadi kecelakan sepanjang hamper tahunnya. Yang menyebabkan adanya korban luka hingga kematian.Oleh sebab itu penelitian ini menarik untuk dilakukan dalam rangka member masukan kepada perusahaan agar tercipta lingkungan kerja yang aman dan sehat untuk mencegah terjadinya kecelakaan di kemudian hari, dan juga dapat meningkatkan produktifitas kerja. Menyusun prosedur kerja menjadi salah satu prioritas penelitan dalam rangka menerapkan Jometode penelitian kuantitatif yang berbentuk angka dan sifatnya dapat dihitung di ukur jumlahnya untuk diolah menggunakan metode statistic yang meliputi mempelajari dan melaporkan setiap bentuk penerapan sistem jaminan keselamtan, dan kesehatan kerja dan memberikan penyuluhan kepada semua karyawan perusahaan dan dan menentukan jalan terbaik mengurangi masalah tersebut dan mengeliminasi bahaya menggunakan metode keselamatan, dan kesehatan kerja pada industry galangan tersebut. Dalam penelitian ini teknik yang di gunakan untuk mengumpulkan data penelitian, yaitu dengan kuesioner sebagai instrument untuk menjawab seperangkat pertanyaan atau pernyataan tertulis kepada respondenuntuk mengetahui efek dari sistem jaminan dan penerapan keselamatan, dan kesehatan kerja. Dari hasil penelitian tersebut terdapat hasil dan pembahasan penelitian, dari kedua kuisioner yang dimana keduanya mendapat jawaban sangat setuju yang tinggi dari para responden.
\end{abstract}

Kata Kunci:Jaminan, Kesehatan, Keselamatan Kerja

\begin{abstract}
General safety issues at PT. Batamec Shipyard Batam still needs attention. Data on injuries that have occurred that are mild and even cause death show that work accidents have occurred in 2014-2015. Based on information from the management, research on risk control is rarely done, while on the other hand the fact that accidents occur throughout the year. Which causes injuries to death. Therefore this research is interesting to do in order to give input to companies to create a safe and healthy work environment to prevent accidents in the future, and also can increase work productivity. Arranging work procedures is one of the research priorities in order to apply quantitative research methods in the form of numbers and can be calculated in terms of the amount to be processed using statistical methods which include studying and reporting every form of safety, health and occupational health systems and providing information to all employees the company and and determine the best way to reduce the problem and eliminate the danger of using safety and health methods in the shipyard industry. In this research the technique used to collect research data, namely by questionnaire as an instrument to answer a set of questions or written statements to respondents to find out the effects of the guarantee system and the application of occupational safety and health. From the results of the study there are results and discussion of the research, from the two questionnaires where both of them received highly agree answers from the respondents.
\end{abstract}

Keywords: Guarantee, Health, Safety 


\section{PENDAHULUAN}

Resiko kegagalan pada setiap aktifitas pekerjaan, dan saat kecelakaan kerja terjadi, seberapapun kecilnya, akan mengakibatkan efek kerugian. Oleh karena itu sebisa mungkin dan sedini mungkin, potensi kecelakaan kerja harus dicegah atau setidak-tidaknya dikurangi dampaknya. Penanganan masalah keselamatan kerja di dalam sebuah perusahaan harus dilakukan secara serius oleh seluruh komponen pelaku usaha, tidak bisa secara parsial dan diperlakukan sebagai bahasan-bahasan marginal dalam perusahaan.

Keselamatan dan kesehatan dapat membuat para tenaga kerja merasa nyaman dan aman dalam melakukan suatu pekerjaan, sehingga dapat memperkecil atau bahkan mewujudkan kondisi nihil kecelakaan dan penyakit kerja. Hal ini juga dijelaskan oleh Ibrahim Jati Kusuma dalam penelitiannya mengenai Pelaksanaan Program Keselamatan dan Kesehatan Kerja

Untuk itu perlunya jaminan keselamatan, dan kesehatan kerja pada suatu perusahaan agara terciptanya kenyaman dan keamanan sebelum dan sesudah memulai pekerjaan tersebut.

Keselamatan dan Kesehatan Kerja (K3) adalah salah satu bentuk upaya untuk menciptakan tempat kerja yang aman, sehat, bebas dari pencemaran lingkungan, sehingga dapat melindungi dan bebas dari kecelakaan kerja pada akhirnya dapat meningkatkan efisiensi dan produktivitas kerja. Kecelakaan kerja tidak saja menimbulkan korban jiwa tetapi juga kerugian materi bagi pekerja dan pengusaha, tetapi dapat mengganggu proses produksi secara menyeluruh, merusak lingkungan yang pada akhirnya akan berdampak pada masyarakat luas. Visi Pembangunan Kesehatan di Indonesia yang dilaksanakan adalah Indonesia Sehat 2010 dimana penduduknya hidup dalam lingkungan dan perilaku sehat, mampu memperoleh layanan kesehatan yang bermutu secara adil dan merata, serta memiliki derajat kesehatan yang setinggi-tingginya (Depkes RI, 2002).

Kondisi kerja yang buruk berpotensi menyebabkan kecelakaan kerja, mudah sakit, stres, sulit berkonsentrasi sehingga menyebabkan menurunnya produktif kerja. Kondisi kerja meliputi variabel fisik seperti distribusi jam kerja, suhu, penerangan, suara, dan ciri-ciri arsitektur tempat kerja lingkungan kerja yang kurang nyaman, misalnya : panas, berisik, sirkulasi udara kurang, kurang bersih, mengakibatkan pekerja mudah stress (Supardi, 2007).

Pelaksanaan Kesehatan dan Keselamatan Kerja (K3) adalah salah satu bentuk upaya untuk menciptakan tempat kerja yang aman, sehat, bebas dari pencemaran lingkungan, 
sehingga dapat mengurangi dan atau bebas dari kecelakaan kerja dan penyakit akibat kerja yang pada akhirnya dapat meningkatkan efisiensi dan produktivitas kerja.

Kecelakaan kerja tidak saja menimbulkan korban jiwa maupun kerugian materi bagi pekerja dan pengusaha, tetapi juga dapat mengganggu proses produksi secara menyeluruh, merusak lingkungan yang pada akhirnya akan berdampak pada masyarakat luas.

PT. Batamec Shipyard merupakan perusahaan galangan kapal terbesar di pulau batam, yang mayoritas konsumenya merupakan perusahaan perusahaan untuk Eropa dan berkelas international.Sebagai perusahaan yang yang bergerak pada bidang industry galangan kapal sudah tentu erat kaitanya dengan resiko kerja dan keselamatan kerja.

Dengan penilitian ini, diharapkan dapat mengatur dan menerapkan sistem sistem keselamatan kerja. Sehingga dapat mengurangi serta mencegah terjadinya kecelakaan kerja pada perusahaan PT. Batamec Shipyard tersebut.

\section{Rumusan Masalah}

Dari latar belakang masalah yang telah dibahas, sering di temukanya masalah kerja yang menyebabkan banyak karyawan terluka serta meniggal dunia.Hal tersebut terjadi karena sistem jamian kerja terkadang tidak diterapkan dan yang di terapkan tidak sesuai dengan standar operasional prosedur.

Adapun masalah pokok pembahasaanya adalah

1. sistem apa saja yang diberikan PT. Batamec Shipyard kepada karyawan berkaitan dengan sistem keselamatan dan kesehatan kerja karyawan?

2. Bagaimana kriteria yang dipakai PT. Batamec Shipyard untuk menentukan batasan batasan penerapan jaminan keselamatan kerja

3. Bagaimana mengukur tingkat keselamatan dan kesehatan pekerja PT Batamec Shipyard dengan menerapkan keselamatan, kesehatan kerja pada para karyawan.

4. Apakah efek sistem jaminan dan penerapan keselamatan, dan kesehatan kerja ini berdampak positif pada karyawan PT Batamec Shipyard.

\section{Kerangka Teori}

\section{Teori Sistem Jaminan Keselamatan Dan Kesehatan Kerja}

Keselamatan dan kesehatan dapat membuat para tenaga kerja merasa nyaman dan aman dalam melakukan suatu pekerjaan, sehingga dapat memperkecil atau bahkan mewujudkan kondisi nihil kecelakaan dan penyakit kerja. Hal ini juga dijelaskan oleh 
Ibrahim Jati Kusuma dalam penelitiannya mengenai Pelaksanaan Program Keselamatan dan Kesehatan Kerja

Adapun sistem dalam jaminan keselamatan dan kesehatan kerja karyawan meliputi:

1) Pelatihan keselamatan dan kesehatan kerja.

Pelatihan Keselamatan dan Kesehatan Kerja (K3) adalah pelatihan yang disusun untuk memberi bekal kepada personil yang ditunjuk perusahaan untuk dapat menerapkan K3 di tempat kerja. Putut Hargiyarto tentang Pelatihan K3 yang dikutip oleh Ibrahim jati kusuma bahwa pelatihan K3 bertujuan agar karyawan dapat memahami dan berperilaku

pentingnya keselamatan dan kesehatan kerja, mengidentifkasi potensi bahaya di tempat kerja, melakukan pencegahan kecelakaan kerja, mengelola bahan-bahan beracun berbahaya dan penanggulangannya, melakukan pencegahan dan pemadaman kebakaran serta menyusun program pengendalian keselamatan dan kesehatan kerja perusahaan.

2) Alat pelindung diri (APD)

Menurut Muhammad Sabir alat pelindung diri (APD) adalah kelengkapan yang wajib digunakan pekerja atau karyawan saat bekerja sesuai kebutuhan untuk menjaga keselamatan pekerja itu sendiri dan orang di sekelilingnya. Pada umumnya alat-alat elindung diri disuatu perusaahn tersebut terdiri adalah helm pengaman (Safety Helmet), Tali Keselamatan (Safety Belt), Sepatu Karet (Sepatu Boot), Sepatu Pelindung (Safety Shoes), Tali Pengaman (Safety Harness), Penutup Telinga (Ear Plug/ Ear Muff), Kacamata Pengaman (Safety Glasses), Masker (Respirator), Pelindung Wajah ( Face Shield ), Jas Hujan ( Rain Coat)

\section{3) Jam kerja}

Untuk karyawan yang bekerja 6 hari dalam seminggu, jam kerjanya adalah 7 jam dalam satu hari dan 40 jam dalam satu minggu. Sedangkan untuk karyawan dengan 5 hari kerja dalam satu minggu, kewajiban bekerja mereka adalah 8 jam dalam satu hari dan 40 jam dalam satu minggu. Hal di atas sangatlah penting diperhatikan dalam sebuah sistem jaminan keselamatan kerja agar sistem jaminan keselamatan yang diterapkan oleh suatu perusahaan itu dapat berjalan dengan baik sesuai yang diharakan.

\section{Batasan - Batasan Penerapan Jaminan Keselamtan Dan Kesehatan Kerja}

Disamping jaminan keselamatan dan kesehatan ini sangatlah penting, namun dalam penerapanya tetap harus ada batasan-batasan yang dimaksud dalam setiap menjalankan program jaminan keselamatan dan kesehatan kerja karyawan, maka tentulah ada batasan- 
batasan dimana batasan itu menjadi pedoman dan ketentuan yang menjadi kebijakan perusahaan dalam menerapkan jaminan keselamatan kerja. Adapun batasan-batasan yang dimaksud tersebut meliputi :

1) Keselamatan kerja (Safety) meliputi 2 konteks yaitu

konteks perorangan dan konteks perusahaan, dalam konteks perorangan merupakan upaya meminimalisasi kontak antara manusia dengan sumber bahaya terutama sebagai pencegahan orang terhadap bahaya yang dapat mengakibatkan penderitaan fisik. Sedangkan dalam konteks perusahaan merupakan kebebasan perusahaan dari bahaya yang dapat merugikan perusahaan baik dari segi keselamatan, kesehatan, keamanan dan pencemaran lingkungan.

2) Insiden

Suatu kejadian yang dapat merugikan perusahaan.

3) kecelakaan

Sebagai suatu peristiwa yang tidak diharapkan, tidak direncanakan, dapat terjadi kapanpun, dalam rangkaian peristiwa yang terjadi karena berbagai sebab yang dapat merugikan fisik (luka / penyakit) terhadap seseorang, Rusaknya harta milik perusahaan, hampir terjadinya usaha atau setiap kombinasi dari efek tersebut.

4)kecelakaan kerja

Kecelakaan yang dialami oleh seorang karyawan, semenjak dia meninggalkan kediamannya menuju tempat kerja selama jam kerja dan jam istirahat maupun sekembalinya dari tempat kerjanya menuju ke rumah.

\section{Teori K3 Di Indonesia Dan Penerapan K3 Di Indonesia}

Keselamatan dan kesehatan kerja mutlak harus dilakukan dalam perusahaan sebagai usaha mencegah dan mengendalikan kerugian yang diakibatkan dari adanya kecelakaan, kebakaran, kerusakan harta benda perusahaan dan kerusakan lingkungan serta bahaya-bahaya lainnya. Sasaran pencapaian pengelolaan K3 adalah tidak adanya kecelakaan kerja yang disertai dengan produktivitas yang tinggi sehingga tujuan perusahaan dapat dicapai secara optimal. Penerapan K3 adalah sebagai usaha penjabaran Undang- Undang No.1 tahun 1970 dari peraturan K3 lainnya dalam melakukan perlindungan terhadap aset perusahaan baik sumber daya manusia dan faktor produksi lainnya. K3 sudah terintegrasi didalam semua fungsi perusahaan baik fungsi perencanaan, produksi dan pemasaran serta fungsi-fungsi lainnya yang ada dalam perusahaan. Tanggung jawab pelaksana K3 di perusahaan merupakan 
kewajiban seluruh karyawan maupun semua orang yang bekerja atau berada dilingkungan perusahaan.Keberhasilan penerapan K3 didasarkan atas kebijakan pengelolaan K3 yang diambil oleh pimpinan perusahaan yaitu komitmen manajemen, kepemimpinan yang tegas, organisasi K3 dalam struktur organisasi perusahaan, sarana dan prasarana yang memadai, integritas K3 pada semua fungsi perusahaan dan dukungan semua karyawan dalam K3.

Keberhasilan penerapan K3 didasarkan atas kebijakan pengelolaan K3 yang diambil oleh pimpinan perusahaan yaitu komitmen manajemen, kepemimpinan yang tegas, organisasi $\mathrm{K} 3$ dalam struktur organisasi perusahaan, sarana dan prasarana yang memadai, integritas K3 pada semua fungsi perusahaan dan dukungan semua karyawan dalam K3. Pada proses penerapan K3 itu sendiri, perusahaan menggunakan filosofi dasar pelaksanaan K3 sebagai berikut:

1. Setiap tenaga kerja berhak mendapatkan perlindungan atas keselamatan dalam melakukan pekerjaan dalam meningkatkan produksi dan produktivitas.

2. Setiap orang lainnya yang berada di tempat kerja perlu jaminan keselamatan.

3. Setiap sumber-sumber produksi yang digunakan secara efisien dan efektif.

4. Pengurus / Pimpinan perusahaan diwajibkan memenuhi dan mematuhi semua syaratsyarat dan ketentuan K3 yang berlaku pada perusahaan dan tempat kerja yang dijalankan.

5. Setiap orang yang memasuki tempat kerja diwajibkan mentaati semua persyaratan K3.

6. Tercapainya kecelakaan nihil.

\section{Tujuan Dan Sasaran Keselamatan Dan Kesehatan Kerja}

Hakikat dan tujuan keselamatan dan kesehatan kerja (K3) yaitu bahwa faktor K3 sangat berpengaruh terhadap efektifitas kerja pada tenaga kerja dan juga berpengaruh terhadap efisiensi produksi dari suatu perusahaan industri, sehingga dengan demikian mempengaruhi tingkat pencapaian produktifitas. Karena pada dasarnya K3 adalah untuk melindungi para tenaga kerja atas hak keselamatanya dalam melakukan pekerjaan dan untuk menciptakan tenaga kerja yang sehat dan produktif. Sehingga upaya pencapaian produktifitas yang semaksimalnya dari suatu perusahaan industri dapat lebih terjamin. Upaya peningkatan keselamatan kerja dan kesehatan kerja ini tidak dapat dipisahkan dengan pencegahan kecelakaan dan gangguan kesehatan, oleh karena itu pencegahan kecelakaan merupakan 
program utama keselamatan dan kesehatan kerja disuatu perusahaan. Adapun tujuan dari keselamatan kerja adalah :

1. Melindungi tenaga kerja atas keselamatannya dalam melakukan pekerjaan untuk kesejahteraan dan meningkatkan produksi serta produktifitas nasional.

2. Menjamin keselamatan setiap orang lain yang berada ditempat kerja.

3. Sumber produksi terpakai secara aman dan efisien

Upaya untuk meningkatkan kesehatan kerja ini juga sangat perlu dilakukan oleh suatu perusahaan karena untuk melindungi para karyawan dari segala gangguan kesehatan dan penyakit. Untuk itu, dalam menerapkan keselamatan dan kesehatan kerja tersebut ada sasaran-sasaran yang harus perhatikan. Sasaran ini terdiri dari 4 tujuan. Adapun tujuan dari adanya sasaran ini adalah

1. Kemanusiaan Berupa usaha untuk mencegah terjadinya penderitaan bagi tenaga kerja dengan demikian terwujudnya kenyamanan, gairah kerja dan kesejahteraan karyawan

2. Ekonomi Berupaya menghindarkan kerugian bagi perusahaan dan kegiatan produksi untuk meningkatkan efisiensi dan produktivitas

3. Sosial Berusaha menciptakan kesejahteraan sosial danmemberikan masyarakat perlindungan terhadap bahayabahaya yang timbul akibat dari kegiatan perusahaan.

4. Hukum Berusaha melaksanakan perundang-undangan yang berlaku dan ditetapkan oleh perusahaan

\section{METODOLOGI}

\section{Desain penelitian}

Variabel penelitian adalah suatu atribut atau sifat atau aspek dari orang maupun obyek yang mempunyai variasi tertentu yang ditetapkan oleh peneliti untuk dipelajari dan ditarik kesimpulannya. Sedangkan Variabel adalah suatu sifat yang dapat memiliki bermacam nilai. Selanjutnya dinyatakan bahwa variabel adalah lambang (symbol) yang mempunyai nilai berupa angka. Jadi variabel merupakan suatu gejala atau sifat dari suatu obyek yang mempunyai variasi atau nilai yang berbeda dengan obyek yang lain yang menjadi fokus peneliti untuk diamati.

Variable - variable yang digunakan adalah sebagai berikut

$\mathrm{X} 1$ = pelatihan keselamatan dan kesehatan kerja.

$\mathrm{X} 2$ = alat pelindung diri (apd)

$\mathrm{X} 3=$ jam kerja 
Kesehatan, dan keselamatan kerja (k3) ( variable terikat y )

Variabel terikat y adalah kesehatan, dan keselamatan kerja diukur berdasarkan fungsi dan tujuan $\mathrm{k} 3$ tersebut.

1. Teori $\mathrm{k} 3$ di indonesia dan penerapan $\mathrm{k} 3$ di indonesia

2. Tujuan dan sasaran keselamatan dan kesehatan kerja

\section{Hipotesis}

Berdasarkan latar belakang penelitian dan kerangka teori penilitian maka dapat disusun hipotesis sebagai berikut

1. Diduga sistem jaminan kerja sangat erat kaitanya dengan penerapan keselamatan, dan kesehatan terhadap para karyawan PT Batamec Shipyard.

\section{Jenis Dan Sumber Data}

Jenis data pada penelitian ini adalah data kuantitatif

Data kuantitatif adalah data penelitian yang berbentuk angka, yang sifatnya dapat dihitung dan diukur jumlahnya untuk di olah menggunakan metode statistik.

1. Data primer yaitu data yang berasal langsung dari objek penelitian, yaitu berupa kusioner yang diberikan secara langsung kepada responden untuk memeperoleh informasi tenteng sistem jaminan dan penerapan kesehatan dan keselamatan kerja $(\mathrm{k} 3)$

2. Data sekunder yaitu data yang diperoleh melalui dokumentasi seperti buku - buku literature dan sumber - sumber lain.

\section{Tekni Pengambilan Sample}

Teknik pengembilan data pada penelitian ini menggunakan teknik pengambilan sampel yang mana menggunakan teknik non random sampling. Hal ini dikarenakan tidak semua individu dalam populasi diikutsertakan menjadi anggota sample. Dalam penelitian ini, sampel yang digunakan peneliti sebanyak 100 responden, sebagai jumlah sample diatas minimal untuk menghindari sample error

\section{Teknik Pengembilan Data}

Teknik pengambilan data menggunakan kuisioner yang diberikan kepada responden pekerja pada pt batamec untuk diisi setelah diberikan penjelasan singkat mengenai kuisoner.

\section{Teknik Analisis Data}

Berdasarkan datav yang dikumpul dari hasil penyebaran kuisioner, data tersebut diolah dan di analisis . teknik analisi ini mengunakan program computer SPSS. Pengujian hipotesis dilakukan dengan model regresi linierberanda. 
Analisi regresi linier berganda dilakukan untuk mengetahui pengaruh sistem jaminan dan penerapan kesehatan, dan keselamatan kerja pada PT Batamec shipyard.

Adapaun rumusnya sebagai berikut

$\mathrm{Y}=\mathrm{b}_{0}+\mathrm{b}_{1 \mathrm{X} 1}+\mathrm{b}_{2 \times 2}+\mathrm{b}_{3 \times 3}$

$\mathrm{Y}=$ Variabel terikat (sitem jaminan)

$\mathrm{B}_{0}=$ koefisien konstanta

$\mathrm{B}_{1+} \mathrm{b}_{2+} \mathrm{b}_{3}=$ Koefisien Regresi

$\mathrm{X} 1$ = pelatihan keselamatan dan kesehatan kerja.

$\mathrm{X} 2$ = alat pelindung diri (apd)

$\mathrm{X} 3$ = jam kerja

\section{Deskripsi Data}

Hasil analisi faktor - faktor pengaruh sitem jaminan kesehatan dan keselamatan kerja pada PT. Batamec Shipyard dari 100 responden.

Table 1. kelompok responden menurut jenis kelamin

\begin{tabular}{|l|l|l|}
\hline Jenis kelamin & Jumlah Responden & Dalam [persen \\
\hline \hline Pria & 59 & 59,0 \\
wanita & 41 & 41,0 \\
\hline total & 100 & 100,0 \\
\hline
\end{tabular}

Table 2. kelompok responden menurut jenis pekerjaan

\begin{tabular}{|c|c|c|}
\hline Pekerjaan & Jumlah responden & Dalam persen \\
\hline \hline Welder & 35 & 35,0 \\
Pitter & 24 & 24,0 \\
Elektical & 22 & 22,0 \\
Painting & 16 & 16,0 \\
lifting & 3 & 3,0 \\
\hline total & 100 & 100,0 \\
\hline
\end{tabular}

\section{Analisis frekuensi tanggapan responden terhadap item - item pertanyaan}

Berdasarkan hasil jawaban kuisioner yang telah disebarkan kepada responden, maka dapat di ketahui reaksi karyawan PY Batamec Shipyard Batam dalam sitem penjaminan dan 
penerapan keselamatan dan kesehatan kerjab (K3) terhadap karyawan PT Batamec shipyard Batam.

1. tanggapan karyawan mengenai jaminan keselamtan, dan kesehatan kerja .

2. Tanggapann karyawan mengenai efek keselamatan dan kesehatan kerja (k3).

Kedua item tersebut disusun dalam bentuk pertanyaan dengan 5 pilihan jawaban yaitu , sangat stuju (SS), Setuju (S), Netral (N), Tidak setuju (TS), Sangat tidak setuju (STS).

\section{Jawaban Responden}

Tabel 4 jawaban responden mengenai jaminan keselamatan, dan kesehatan kerja (k3)

\begin{tabular}{|c|c|c|}
\hline Skala jawaban & frequensi & Persenan (\%) \\
\hline \hline Sangat setuju & 51 & 51,0 \\
\hline Setuju & 31 & 31,0 \\
\hline Netral & 18 & 0 \\
\hline Tidak setuju & 0 & 0 \\
\hline Sangat tidak setuju & 0 & 100 \\
\hline total & 100 & $\mathrm{k}$ \\
\hline
\end{tabular}

Keterangan : jawaban responden mengenai jaminan keselamatan, dn kesehatan kerja $(\mathrm{k} 3)$ maka, terdapat dengan jumlah sangat setuju 51 frequensi responden, dalam persen (\%) 51,0, setuju 31 frequensi responden dan dalam persen (\%) 31,0, netral 18 prequnsi responden dan dalam persenan (\%) 18,0, tidak setju 0 prequensi responden dan dalam persen (\%) 0 , dan terahir sanat tidak setuju 0 prequensi responden dan dalam persen $(\%) 0,0$.

Tabel 5 Jawaban responden mengenai penerapan keselamatan, kesehatan kerja

\begin{tabular}{|c|c|c|}
\hline Skala jawaban & frequensi & Persenan (\%) \\
\hline \hline Sangat setuju & 78 & 78,0 \\
\hline Setuju & 20 & 20,0 \\
\hline Netral & 2 & 2,0 \\
\hline Tidak setuju & 0 & 0 \\
\hline Sangat tidak setuju & 0 & 0 \\
\hline Total & 100 & 100 \\
\hline
\end{tabular}

Keterangan: jawaban responden mengenai penerapan keselamatan, dan kesehatan kerja (K3) maka terdapat dengan jumlah 78 prequensi responden sangat setuju, dan dalam persen $(\%)$ 
78,0, setuju 20 prequensi responden dan dalam persen (\%) 20,0, netral 2 prequensi responden dan dalam persen (\%) 2,0, tidak setuju 0 prequensi responden dan dalm persen (\%) 0,0 , terahir sangat tidak setuju 0 prequensi responden dan dalam persen (\%) 0,0 .

\section{REFERENSI}

Andhika, P.A., 2012, "Studi Sistem Instrumentasi Pada Industri Proses", http://praditakhalisandhika.blogspot.com/2012/04/penerapan-k3.html.

Arikunto, S., 2006, Prosedur Penelitian Kualitatif, PT. Rineka Cipta, Jakarta.

Azmi D, R., 2008, "Penerapan Sistem Manajemen Keselamatan dan KesehatanKerja oleh P2K3 untuk meminimalkan kecelakaan kerja di PT. Wijaya

Direktorat Pengawasan Norma Keselamatan Dan Kesehatan Kerja, 2006 "Himpunan Perundang-undangan Keselamatan dan Kesehatan Kerja”. 